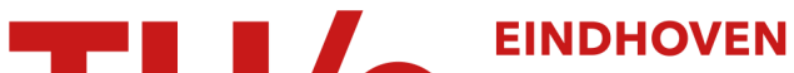 \\ UNIVERSITY OF \\ TECHNOLOGY
}

\section{Safety and feasibility of local myocardial hypothermia}

Citation for published version (APA):

Otterspoor, L. C., van 't Veer, M., van Nunen, L. X., Wijnbergen, I. F., Tonino, W. A. L., \& Pijls, N. H. J. (2016). Safety and feasibility of local myocardial hypothermia. Catheterization and Cardiovascular Interventions, 87(5), 877-883. https://doi.org/10.1002/ccd.26139

DOI:

$10.1002 / \mathrm{ccd} .26139$

Document status and date:

Published: 01/04/2016

\section{Document Version:}

Publisher's PDF, also known as Version of Record (includes final page, issue and volume numbers)

\section{Please check the document version of this publication:}

- A submitted manuscript is the version of the article upon submission and before peer-review. There can be important differences between the submitted version and the official published version of record. People interested in the research are advised to contact the author for the final version of the publication, or visit the $\mathrm{DOI}$ to the publisher's website.

- The final author version and the galley proof are versions of the publication after peer review.

- The final published version features the final layout of the paper including the volume, issue and page numbers.

Link to publication

\section{General rights}

Copyright and moral rights for the publications made accessible in the public portal are retained by the authors and/or other copyright owners and it is a condition of accessing publications that users recognise and abide by the legal requirements associated with these rights.

- Users may download and print one copy of any publication from the public portal for the purpose of private study or research.

- You may not further distribute the material or use it for any profit-making activity or commercial gain

- You may freely distribute the URL identifying the publication in the public portal.

If the publication is distributed under the terms of Article 25fa of the Dutch Copyright Act, indicated by the "Taverne" license above, please follow below link for the End User Agreement:

www.tue.nl/taverne

Take down policy

If you believe that this document breaches copyright please contact us at:

openaccess@tue.nl

providing details and we will investigate your claim. 


\title{
Safety and Feasibility of Local Myocardial Hypothermia
}

\author{
Luuk C. Otterspoor, ${ }^{1,2}$ MD, Marcel van't Veer, ${ }^{1,2}$ MSC, PhD, Lokien X. van Nunen, ${ }^{1,2}$ MD, \\ Inge Wijnbergen, ${ }^{1}$ MD, Pim A.L. Tonino, ${ }^{1}$ MD, PhD, and Nico H.J. Pijls, ${ }^{1,2 *}$ MD, PhD
}

\begin{abstract}
Background: In ST-elevation myocardial infarction (STEMI), reduction in time to reperfusion of the occluded coronary artery reduces infarct size. In animal models, an additional reduction of infarct size was observed when hypothermia was induced before reperfusion, despite a longer ischemic time. However, several human studies did not corroborate this positive effect, which is believed to be in part due to the inability of systemic induced hypothermia to induce sufficient decrease of local myocardial temperature before reperfusion. Providing rapid local myocardial hypothermia by intracoronary infusion of saline before reperfusion in patients with STEMI may overcome this problem. In this study, we evaluate the safety and feasibility of providing rapid intracoronary myocardial hypothermia in patients undergoing intracoronary blood flow measurements based on thermodilution with continuous infusion of saline at room temperature. Methods and Results: In 53 patients with stable angina (SA) and 20 patients with STEMI, a total of 215 measurements were performed. The measurements consisted of continuous selective intracoronary infusion of saline at room temperature with rates between $10 \mathrm{ml} / \mathrm{min}$ and $30 \mathrm{ml} /$ min. Temperature changes compared to initial blood temperature $\left(T_{b}\right)$ were measured at the tip of the infusion catheter $\left(T_{\mathrm{i}}\right)$ and distally in the coronary artery $\left(T_{\mathrm{d}}\right)$. In patients with SA, $T_{\mathrm{i}}$ was $-5.65 \pm 1.41^{\circ} \mathrm{C}$ (range -9.27 to -2.28 ) and $T_{\mathrm{d}}$ was $-0.78 \pm 0.51^{\circ} \mathrm{C}$ (range -3.27 to $-0.23^{\circ} \mathrm{C}$ ). In patients with STEMI, $T_{\mathrm{i}}$ was $-7.45 \pm 0.51^{\circ} \mathrm{C}$ (range -8.21 to -6.56 ) and $T_{\mathrm{d}}$ was $-1.37 \pm 0.82^{\circ} \mathrm{C}$ (range -4.62 to $-0.74^{\circ} \mathrm{C}$ ). In all patients, steady-state intracoronary hypothermia was achieved within $15 \mathrm{sec}$ and could be maintained without noticeable complications. Conclusion: This study demonstrates the safety and feasibility of inducing intracoronary hypothermia by selective infusion of saline at room temperature in patients with SA and STEMI. Steady-state hypothermia could be achieved and maintained quickly, easily, and safely using common PCI techniques. Therefore, our findings warrant further studies to the use of intracoronary hypothermia to enhance myocardial salvage in acute myocardial infarction. () 2015 Wiley Periodicals, Inc.
\end{abstract}

Key words: myocardial hypothermia; percutaneous coronary interventions; myocardial reperfusion injury; ST-elevation myocardial infarction

\section{INTRODUCTION}

In ST-elevation myocardial infarction (STEMI), early reperfusion is of paramount importance to limit infarct size and create optimal conditions for favorable long-term outcome.

Currently, the gold standard for achieving fast reperfusion is primary percutaneous coronary intervention (PPCI) $[1,2]$. However, notwithstanding the merits of PPCI, the reperfusion process itself may contribute to secondary damage to the myocardium, called "reperfusion injury" [3-6]. Mild hypothermia, i.e. the cooling of endangered myocardial tissue to $33^{\circ} \mathrm{C}$ $\left(91.4^{\circ} \mathrm{F}\right)$, which is preferably induced already before reperfusion with blood, may attenuate this reperfusion injury.

Animal studies in a variety of species have shown that the induction of hypothermia before reperfusion of an acute coronary occlusion reduces infarct size [7-14].
If hypothermia is initiated after reperfusion, this effect is not observed $[10,15,16]$. Human studies on the other hand have not been able to show a reduction in infarct

\footnotetext{
${ }^{1}$ Department of Cardiology, Catharina Hospital, Eindhoven, The Netherlands

${ }^{2}$ Department of Biomedical Engineering, University of Technology, Eindhoven, The Netherlands
}

Conflict of interest: Dr. Pijls receives institutional research grants from, and is consultant for St Jude Medical.

*Correspondence to: Nico H.J. Pijls, MD, PhD, Department of Cardiology, Catharina Hospital, Eindhoven Michelangelolaan, 25623 EJ, Eindhoven, The Netherlands. E-mail: nico.pijls@inter.nl.net

Received 10 February 2015; Revision accepted 11 July 2015

DOI: $10.1002 /$ ccd.26139

Published online 13 August 2015 in Wiley Online Library

(wileyonlinelibrary.com) 
size [17-24]. This may be attributable to the fact that, in the majority of the patients, a therapeutic level of hypothermia was not reached before reperfusion [17-21]. In these studies, whole body hypothermia (with an endovascular cooling system in combination with cold saline) was used, limiting efficacy in terms of rapid and sufficient cooling of the endangered myocardium and leading to adverse systemic reactions such as shivering and an enhanced adrenergic state.

Local intracoronary induction of hypothermia may accelerate achieving the target level of hypothermia while simultaneously preventing the systemic adverse effects. This intracoronary application of hypothermia has been investigated in two animal studies so far $[7,25]$. In the first study, Kim et al. evaluated the safety and feasibility of this intracoronary method in pigs [25]. In the second study, Otake et al. demonstrated a significant reduction in myocardial necrosis when using intracoronary hypothermia in pigs with 60 min of coronary occlusion [7].

In the present study, we aimed to evaluate the safety and feasibility of intracoronary hypothermia by means of selective intracoronary infusion of saline at room temperature at a rate of $10-30 \mathrm{ml} / \mathrm{min}$ in patients with stable angina (SA) and patients with acute myocardial infarction immediately following PPCI, and after 3-5 days.

\section{METHODS}

\section{Study Population}

Data were collected from two patient groups undergoing intracoronary blood flow measurements using thermodilution with continuous infusion of saline. A technique described in detail before [26,27]. The first group consisted of 53 patients with SA in whom measurements were performed as part of a previous study protocol [27] or as routine intracoronary blood flow measurements. The second group consisted of 20 patients with STEMI in whom measurements were performed immediately after PPCI and after 3-5 days [28]. These patients participated in a previous study regarding changes in the microcirculation in acute myocardial infarction. Both studies mentioned above and the use of data for the present analysis have been approved by the institutional review board of the Catharina hospital, and informed consent was obtained from all patients. In the second group of patients, informed consent was obtained immediately after PPCI.

\section{Instrumentation}

The application of continuous intracoronary infusion of saline and the principle of thermodilution is extensively described by Aarnoudse et al. [27] and Wijnber- gen et al. [28]. In short, the instrumentation is as follows (Fig. 1).

A standard sensor-tipped pressure/temperature guidewire (PressureWire Certus, St. Jude Medical systems, St. Paul, MN) is advanced into the distal part of the index coronary artery. It should be noted that this pressure/temperature guidewire is zeroed at baseline and is only able to measure temperature differences and not the actual blood temperature itself. Hereafter, an infusion catheter with four side holes is advanced over the wire into the coronary artery. In a normal, not significantly diseased coronary artery, the tip of the infusion catheter is placed within the first segment of the coronary artery. In case of a stenotic coronary artery, the tip of the infusion catheter is placed just proximal to the stenosis. In case of STEMI, the infusion catheter is placed at the location of the opened occlusion, i.e. within the stent, in order to measure blood flow in the area at risk. The position of the pressure/temperature sensor is always $3-6 \mathrm{~cm}$ distal to the tip of the infusion catheter, as previously described [15].

Coronary hyperemia is induced by central venous adenosin infusion. After achieving steady-state maximum coronary hyperemia, saline at room temperature (approximately $20^{\circ} \mathrm{C}$ or $68^{\circ} \mathrm{F}$ ) is infused at a constant rate through the infusion catheter using a contrast infusion pump (Agiomat 6000, Lieber-Flarsheim). The rate of saline infusion was estimated based upon the size of the coronary artery and the location of infusion, and varied from 10 to $30 \mathrm{ml} / \mathrm{min}$, as previously described.

Differences in the temperature at the sensor close to the tip of the wire in the distal coronary artery $\left(T_{\mathrm{d}}\right)$ (after complete mixing of blood with the infused saline) are measured and recorded for approximately 30-60 sec. Thereafter, the sensor is pulled back into the infusion catheter, thereby measuring the temperature of the infused saline $\left(T_{\mathrm{i}}\right)$. Volumetric blood flow in the respective coronary artery can be calculated then as described by Van't Veer et al. [26], but was not the aim of the present study.

\section{Measurements and Statistics}

In the patients with SA, standard angiography was performed, followed by fractional flow reserve (FFR) measurements and absolute flow measurements. If the FFR was $\leq 0.80$, a stent was placed and the measurements were repeated after stenting.

In patients with acute ST segment elevation myocardial infarction, PPCI with stenting was performed routinely and the absolute flow measurements were performed immediately thereafter [28]. In these patients, measurements were repeated after 3-5 days. In all procedures, registrations were continuously displayed and infusion flow $\left(Q_{\mathrm{i}}\right)$ and temperatures $\left(T_{\mathrm{i}}\right.$ and

Catheterization and Cardiovascular Interventions DOI 10.1002/ccd.

Published on behalf of The Society for Cardiovascular Angiography and Interventions (SCAI). 


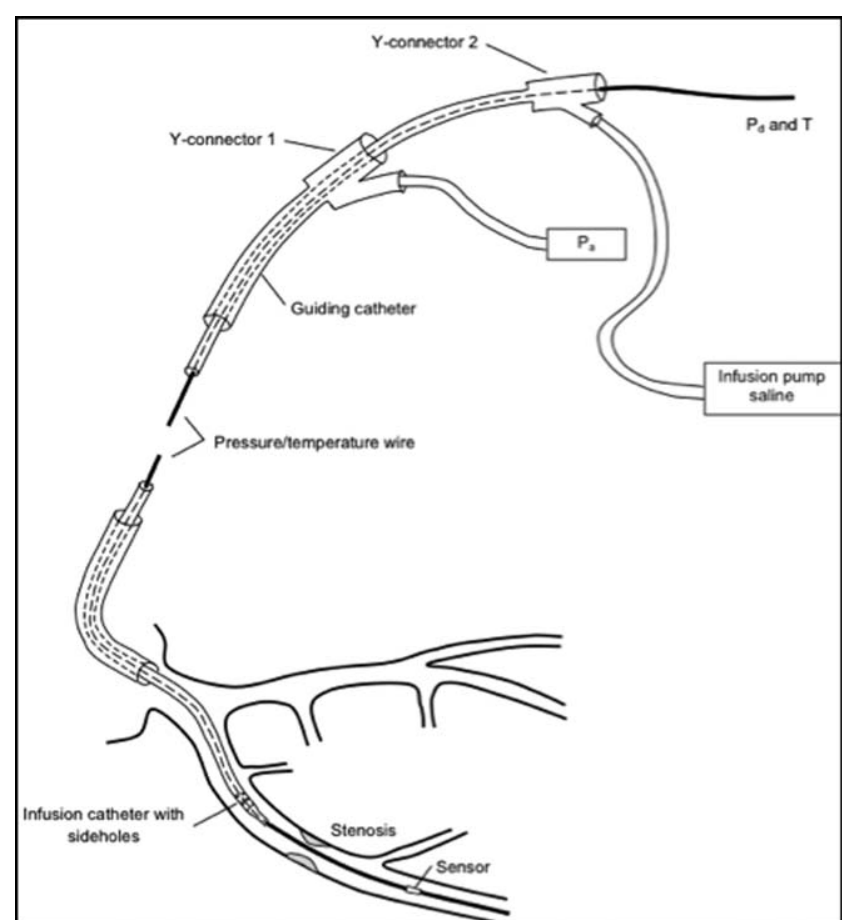

Fig. 1. Schematic drawing, showing the instrumentation in the left circumflex artery to provide hypothermia for coronary blood flow measurements. A 2.8-Fr infusion catheter is advanced over a 0.014-inch pressure/temperature (temp) sensor-tipped guidewire through a $Y$-connector $\left(Y_{1}\right)$ and positioned proximal to the stenosis (if present) and with its side holes in a segment without major side branches. The infusion catheter is connected to an infusion pump by a second $Y$ connector (Y2), enabling continuous infusion of saline at room temperature $(10-30 \mathrm{ml} / \mathrm{min})$. The sensor-tipped guidewire is connected to the interface (AnalyserXpress, St Jude Medical, St. Paul, MN-Analyzer) as routinely done in coronary pressure measurement, and distal coronary pressure $\left(\boldsymbol{P}_{\mathrm{d}}\right)$ and temperature $\left(T_{\mathrm{d}}\right)$ are displayed on the interface. The aortic pressure $(\mathrm{Pa})$, measured at the tip of the guiding catheter, is recorded by a regular pressure transducer and also displayed on the interface. For the purpose of intracoronary hypothermia, without the goal of measurement of absolute coronary blood flow, no specific infusion catheter is mandatory and a simple over-the-wire-balloon can be used (see text).

$T_{\mathrm{d}}$ ), as well as coronary and aortic pressures, were recorded. Accuracy and reproducibility of flow measurements by this technique have been described previously [27].

No infusion rates below $10 \mathrm{ml} / \mathrm{min}$ were used in any of the patients to avoid an unfavorable signal-to-noise ratio. Infusion rates above $30 \mathrm{ml} / \mathrm{min}$ were not used because in all patients, infusion rates of $10-30 \mathrm{ml} / \mathrm{min}$ were sufficient for the purpose of absolute flow measurements performed in the initial studies.

With respect to safety, special attention was given to possible conduction disorders and arrhythmias. To investigate feasibility, we evaluated the ease of the technique, the time requiring instrumentation and the time required to achieve steady-state hypothermia in the distal coronary artery.

All data are presented as mean $\pm \mathrm{SD}$, followed by the range for the continuous variables.

\section{RESULTS}

The instrumentation could be performed easily and without complications in all patients within $10 \mathrm{~min}$. An example of such a measurement is presented in Fig. 2. In total, 215 measurements were performed in 73 patients, 53 of which had SA and 20 patients who presented with STEMI. In the SA patients, the index artery was the left anterior descending artery (LAD) in 29 patients, the left circumflexus artery (LCX) in 5 patients, and the right coronary artery (RCA) in 19 patients, respectively. In the STEMI patients, the index artery was the LAD in 8 patients, the LCX in 4 patients, and the RCA in 8 patients. In all patients, an infusion of saline at room temperature with rates between $10 \mathrm{ml} / \mathrm{min}$ and $25 \mathrm{ml} / \mathrm{min}$ was used, except in one patient in whom a rate of $30 \mathrm{ml} /$ min was used. $T_{\mathrm{i}}$ in patients with $\mathrm{SA}$ was $-5.65 \pm 1.41^{\circ} \mathrm{C}$ (range -9.27 to $-2.28^{\circ} \mathrm{C}$ ) and $T_{\mathrm{d}}$ was $-0.78 \pm 0.51^{\circ} \mathrm{C}$ (range -3.27 to $-0.23^{\circ} \mathrm{C}$ ). In patients with STEMI, $T_{\mathrm{i}}$ was $-7.45 \pm 0.51^{\circ} \mathrm{C}$ (range -8.21 to $-6.56^{\circ} \mathrm{C}$ ) and $T_{\mathrm{d}}$ was $-1.37 \pm 0.82^{\circ} \mathrm{C}$ (range -4.62 to $\left.-0.74^{\circ} \mathrm{C}\right)$.

In all patients, steady-state hypothermia in the distal artery was achieved within $15 \mathrm{sec}$ after start of the infusion, and disappeared completely within $10 \mathrm{sec}$ after discontinuing the infusion. There was a clear and reproducible relation between infusion rate and temperature at the tip of the infusion catheter $\left(T_{\mathrm{i}}\right)$ but, as expected, a large variation in distal coronary temperature was observed related to blood flow, the size of the coronary artery, its perfusion territory, and possibly intramyocardial resistance (Fig. 3). Three patients experienced short periods of second degree atrioventricular (AV)-block, without symptoms. One of these was the patient who had an infusion rate of $30 \mathrm{ml} / \mathrm{min}$.

From Fig. 3, it can be observed that at very low coronary flow (as in an occluded coronary artery), distal blood temperature $T_{\mathrm{d}}$ approaches infusion temperature $T_{\mathrm{i}}$ and that it is feasible to achieve $4^{\circ} \mathrm{C}$ of hypothermia with the present infusion rates. With higher blood flow, distal temperature increases as expected and higher infusion rates or lower infusion temperatures (i.e., cold saline) will be necessary to achieve the desired hypothermia $\left(33^{\circ} \mathrm{C}\right)$ in the distal coronary artery.

Catheterization and Cardiovascular Interventions DOI 10.1002/ccd. Published on behalf of The Society for Cardiovascular Angiography and Interventions (SCAI). 


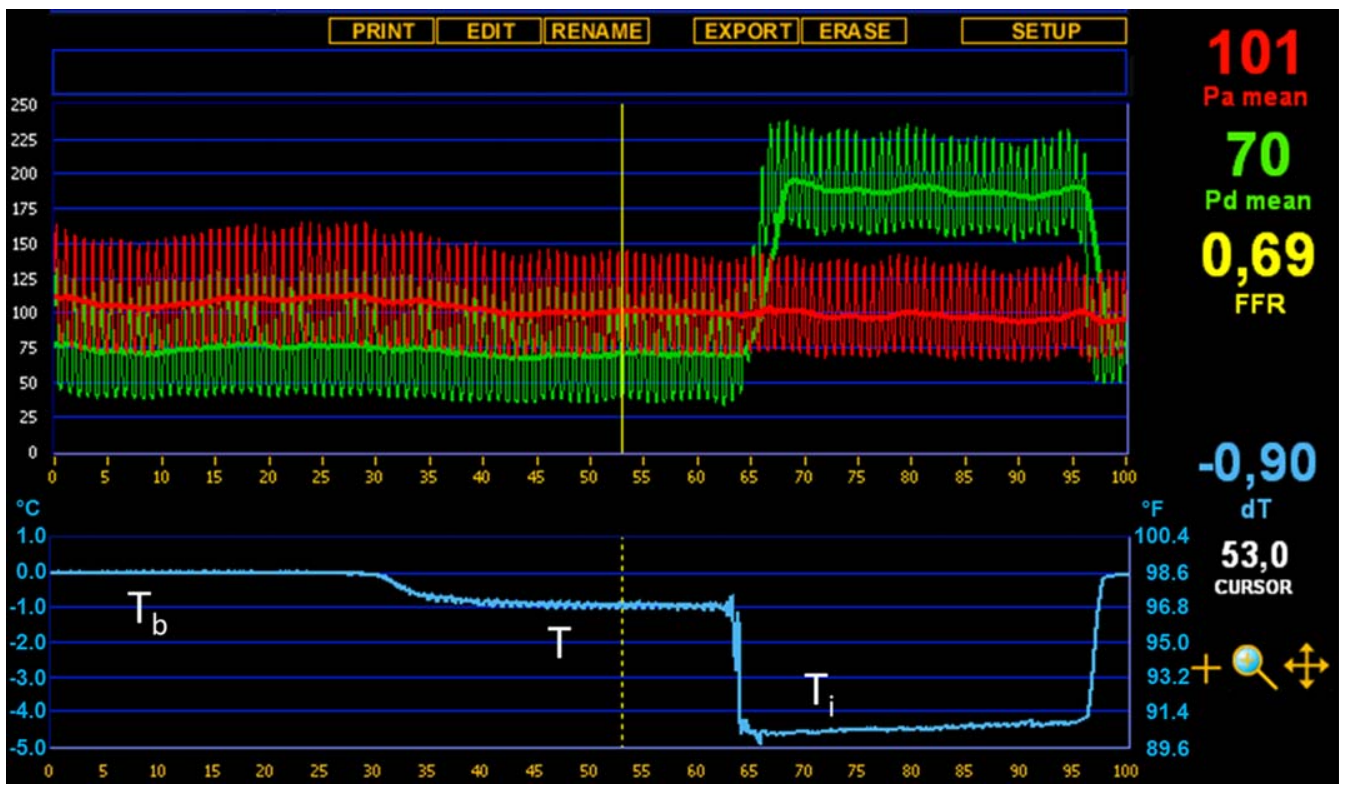

Fig. 2. Representative figure showing a complete recording of intracoronary temperature and pressure measurements. The left scale expresses temperature in ${ }^{\circ} \mathrm{C}$ relative to blood temperature. The right hand scale expresses temperature in absolute ${ }^{\circ} \mathrm{F}$. Blood temperature is set to 0 at the beginning of the measurement $\left(T_{\mathrm{b}}\right)$. Thereafter infusion of saline at room temperature is initiated (at $30 \mathrm{sec}$ ). Temperature of the saline mixed with coronary blood declines rapidly and is measured in the distal coronary artery $\left(T_{\mathrm{d}}\right)$. Steady-state hypothermia rapidly develops and lasts in this case for $65 \mathrm{sec}$, whereafter the sensor is pulled back into the infusion catheter to obtain the temperature of the saline when it enters into the coronary artery $\left(T_{\mathrm{i}}\right)$.

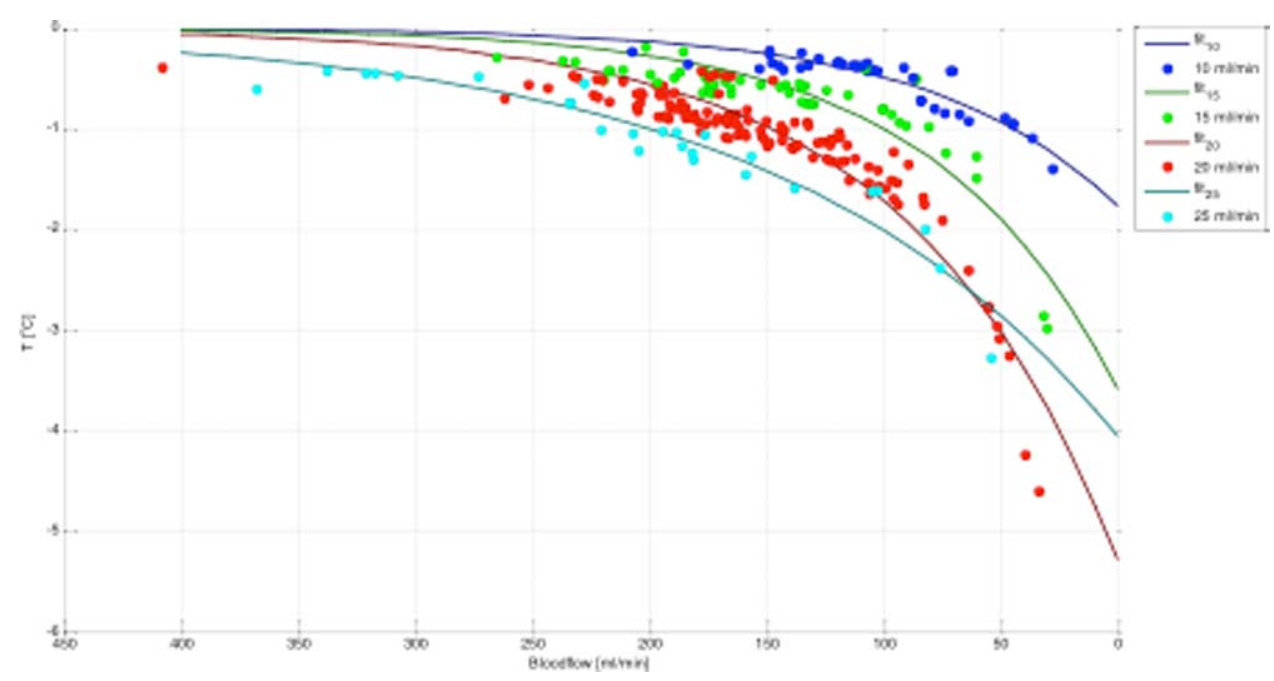

Fig. 3. Demonstration of the relation between coronary temperature $\left(T_{\mathrm{d}}\right)$, coronary blood flow, and saline infusion flow, for four different infusion rates. If coronary blood flow approaches zero, the temperature within the coronary artery becomes identical to the temperature of the infused saline. If the coronary blood flow is higher, the coronary blood temperature increases. With higher infusion rates, the coronary blood temperature decreases more.

\section{DISCUSSION}

In this study, we evaluated the safety and feasibility of intracoronary hypothermia induced by selective intracoronary infusion of saline at room temperature in patients with SA and ST-elevation myocardial infarction. Apart from mild and transitional conduction disturbances, no adverse effects were noted. Moreover, from 
a technical point of view, the instrumentation could be performed within $10 \mathrm{~min}$, even in the acute setting of patients who had just undergone PPCI because of STEMI. Steady-state coronary hypothermia was achieved within $15 \mathrm{sec}$ from the start of infusion in all cases which is much more rapidly than in any previous study. These results prove the safety and feasibility of intracoronary hypothermia and may have implications for future trials, in which intracoronary hypothermia is studied as an addition to primary PCI to enhance salvage of myocardium in patients with STEMI.

Although primary PCI is the gold standard for restoring epicardial blood flow in the setting of STEMI and the first step to myocardial salvage, the reperfusion process itself may contribute to secondary myocardial injury and cardiomyocyte death. This reperfusion injury may account for nearly half of the final infarct size $[4,5]$ and refers to the death of cardiomyocytes that were still viable at the end of the ischemic event. The phenomenon of reperfusion injury is incompletely understood and currently there is no established therapy for preventing it. Contributory factors are intramyocardial edema with compression of the microvasculature, oxidative stress, calcium overload, mitochondrial transition pore opening, microembolization, neutrophil plugging, and hypercontracture [4,5,29,30]. This results in myocardial stunning, reperfusion arrhythmias, and ongoing myocardial necrosis. Myocardial stunning refers to the post-ischemic contractile dysfunction and is reversible in part. Reperfusion arrhythmias usually are self-terminating and are easily treatable.

Myocardial hypothermia may attenuate the unfavorable mechanisms mentioned above. However, limited data are available on the beneficial mechanisms of hypothermia to protect the myocardium from reperfusion damage. In animals, several studies demonstrated a protective effect of hypothermia on the infarction area $[7,9,11,31]$. This effect was only noted when hypothermia was established before reperfusion. Hypothermia is therefore thought to attenuate reperfusion damage by oxidative stress [32-34], release of cytokines, and development of interstitial or cellular edema [35-37]. It has been shown in animals that induced hypothermia resulted in increased ATP-preservation in the ischemic myocardium compared to normothermia [38-40].

The intracoronary use of hypothermia by infusing saline was investigated in two previous studies. Kim et al. showed feasibility of intracoronary cooling during ischemic conditions as well as during acute myocardial infarction [25]. Seven out of fourteen pigs died from ventricular fibrillation during the study protocol, but outside the cooling phases, most likely due to the large ischemic area and the susceptibility of pigs to arrhythmias during ischemic events. Otake et al. dem- onstrated intracoronary use of hypothermia to be safe and effective in preventing myocardial necrosis [7]. In their study, saline of $4^{\circ} \mathrm{C}$ was used without complications (such as vasospasm, hemodynamic instability, or bradycardia) and it even attenuated ventricular arrhythmias significantly. However, using an infusion rate of $2.5 \mathrm{ml} / \mathrm{min}$, myocardial temperature lowering by $-3^{\circ} \mathrm{C}$ was possible after $\sim 45 \mathrm{~min}$. Limited by their equipment, higher infusion rates were not possible, but could have been useful to obtain the desired myocardial temperature more rapidly.

In humans however, induction of local hypothermia in the infarcted area only has not been investigated at all. Human studies on hypothermia for infarct size reduction used total body hypothermia, and failed to show a protective effect. The two first clinical trials investigating mild systemic hypothermia using endovascular cooling catheters as an adjunct to PPCI in myocardial infarction failed to show a reduction in infarct size $[17,22,24,41]$. This is thought to be due to the inability to achieve sufficient hypothermia quickly enough $\left(<35^{\circ} \mathrm{C}\right)$ at onset of reperfusion. A subgroup analysis of these two trials showed a strong trend toward a positive effect in patients who did reach the target temperature $<35^{\circ} \mathrm{C}$ [24]. Gotberg et al. demonstrated a reduction of infarct size of $38 \%$ in the RAPID MI-ICE study, in which the combination of an endovascular cooling system and systemic infusion of cold saline was used [20]. However, the primary end point was the safety and feasibility of this cooling method and the results should be interpreted with care regarding the small study sample. They repeated the study protocol in 120 patients (CHILL-MI trial), but were not able to confirm the cardioprotective effects of this form of systemic cooling [21]. The disappointing results in human studies are possibly due to the necessity of systemic hypothermia up until now, which is associated with a long time interval to obtain sufficient hypothermia-if obtained at all-, and to the severe side effects of systemic cooling, such as severe shivering, which prevents the ischemic myocardium from attaining the targeted temperature. In animal models this shivering was prevented by sedation.

The use of an intracoronary infusion catheter allows selective infusion of a relatively large amount of saline in a fast way. Our data show that the technique to advance an infusion catheter is safe and can be performed quickly in the setting of primary PCI. The blood temperature drops rapidly after start of the infusion. Within less than $15 \mathrm{sec}$, steady-state hypothermia is achieved in the distal coronary artery and in the blood entering the myocardium. However, in the majority of these patients these temperature drops were not yet in the therapeutic range. Despite the fact that target temperatures of $T_{\mathrm{d}}$ as defined for mild hypothermia $\left(<33^{\circ} \mathrm{C}\right)$

Catheterization and Cardiovascular Interventions DOI 10.1002/ccd Published on behalf of The Society for Cardiovascular Angiography and Interventions (SCAI). 
were reached in a minority of the patients, it is very likely that with a higher infusion rate of saline at room temperature or with saline moderately below room temperature, it will be able to cool the infarcted myocardium to a temperature of $33^{\circ} \mathrm{C}$ within minutes in case of an occluded artery in most patients. During occlusion, as is the case just prior to PPCI, achievement of sufficiently low temperature will not be a problem (Fig. 3.).

The advantage of administration of intracoronary saline compared to systemic cooling is the ability to obtain hypothermia in the infarcted myocardium both rapidly, and locally, thereby preventing or reducing the adverse systemic effects of hypothermia such as shivering and ensuring the effect only there where it is needed. In our study, no complications such as shivering, hemodynamic instability, coronary vasoconstriction, and bradycardia were observed. Although the time of instrumentation was within the target range in all cases, it is to be expected to be shorter in the case of a dedicated study on hypothermia in STEMI. In contrast to the presently used study protocols for absolute flow measurements, where exact measurement of temperature both in the distal coronary artery and at the tip of the specifically designed infusion catheter are mandatory, during primary PCI a simple over-thewire-balloon can be positioned within the occlusion in the coronary artery, inflated with low atmosphere just to maintain total occlusion, whereafter the guidewire can be removed and the saline can be administered through the lumen of the over-the-wire balloon.

In analogy to the animal experiments, the balloon should be deflated after an arbitrary $10 \mathrm{~min}$ of cooling whereafter cooling can be continued with an open vessel for another $10 \mathrm{~min}$. To further investigate the potential of therapeutic myocardial hypothermia, it is essential to investigate and understand the relationship between blood temperature in the distal coronary artery and the intramyocardial temperature in the area at risk, and thus be able to estimate the real intramyocardial temperature through measuring the temperature distal in the coronary artery $\left(T_{\mathrm{d}}\right)$. This "true" intramyocardial temperature cannot be assessed directly in conscious humans. Therefore, these questions are currently studied in the isolated beating pig heart model [42], a model that allows intramyocardial temperature measurements at multiple locations.

\section{Study Limitations}

This is a retrospective analysis based on data that were collected in two different prospective trials focusing on coronary blood flow measurements and not on intracoronary hypothermia in itself. In these trials, adenosine was infused intravenously as well as contin- uous intracoronary infusion of saline. In future studies focusing on reduction of infarct size in acute myocardial infarction, the administration of adenosine will not be needed, thereby significantly simplifying the procedure.

Second, the infusion time was $\pm 1-2$ min, which is shorter than the desired cooling period and a temperature of $33^{\circ} \mathrm{C}$ was achieved in only a minority of patients, simply because no further decrease of temperature was needed for these respective studies. As discussed above, using a similar technique, it is expected to achieve the target temperature of $33^{\circ} \mathrm{C}$ rapidly in most patients, especially in case of low blood flow as in acute myocardial infarction. It is unknown how long the infusion should be continued to optimize treatment in acute myocardial infarction.

Moreover, the temperature difference in the present analysis disappeared within $10 \mathrm{sec}$ after discontinuation of the infusion. In these patients however, the main goal was calculation of flow, and there was no need for steady-state hypothermia for longer than $60 \mathrm{sec}$.

Finally, temperatures measured in the distal part of the coronary artery do not translate to intramyocardial temperatures. Further experimental studies as mentioned above are mandatory to relate distal coronary blood temperature to myocardial tissue temperature, and are presently performed by our group.

\section{CONCLUSION}

This study demonstrates the safety and feasibility of inducing local intracoronary hypothermia up to $33^{\circ} \mathrm{C}$ by selective intracoronary infusion of saline at room temperature in patients with SA and in acute myocardial infarction. This technique of intracoronary infusion has the advantage of fast and local induction of hypothermia in the infarct zone, without causing adverse systemic effects of hypothermia such as shivering. These findings justify further studies to local therapeutic myocardial hypothermia during primary percutaneous intervention to limit infarct size.

\section{REFERENCES}

1. Gibson CM, et al. Relationship of TIMI myocardial perfusion grade to mortality after administration of thrombolytic drugs. Circulation 2000;101:125-130.

2. Keeley EC, Boura JA, Grines CL. Primary angioplasty versus intravenous thrombolytic therapy for acute myocardial infarction: A quantitative review of 23 randomised trials. Lancet 2003;361:13-20.

3. Murphy E, Steenbergen C. Mechanisms underlying acute protection from cardiac ischemia-reperfusion injury. Physiol Rev 2008;88:581-609.

4. Yellon DM, Hausenloy DJ. Myocardial reperfusion injury. N Engl J Med, 2007;357:1121-1135. 
5. Hausenloy DJ, Yellon DM. Myocardial ischemia-reperfusion injury: A neglected therapeutic target. J Clin Invest 2013;123: 92-100.

6. Kloner RA. Does reperfusion injury exist in humans?. J Am Coll Cardiol, 1993; 21:537-545.

7. Otake H, et al. Catheter-based transcoronary myocardial hypothermia attenuates arrhythmia and myocardial necrosis in pigs with acute myocardial infarction. J Am Coll Cardiol, 2007;49:250-260.

8. Miki T, et al. Mild hypothermia reduces infarct size in the beating rabbit heart: A practical intervention for acute myocardial infarction? Basic Res Cardiol 1998;93:372-383.

9. Chien GL, et al. "Normothermic range" temperature affects myocardial infarct size. Cardiovasc Res 1994;28:1014-1017.

10. Maeng $M$, et al. Hypothermia during reperfusion does not reduce myocardial infarct size in pigs. Basic Res Cardiol 2006; 101:61-68.

11. Dae MW, et al. Effect of endovascular cooling on myocardial temperature, infarct size, and cardiac output in human-sized pigs. Am J Physiol Heart Circ Physiol 2002;282:H1584-H1591.

12. Duncker DJ, et al. Effect of temperature on myocardial infarction in swine. Am J Physiol 1996;270:H1189-H1199.

13. Hale SL, Dave RH, Kloner RA. Regional hypothermia reduces myocardial necrosis even when instituted after the onset of ischemia. Basic Res Cardiol 1997;92:351-357.

14. Schwartz LM, et al. Epicardial temperature is a major predictor of myocardial infarct size in dogs. J Mol Cell Cardiol 1997;29: $1577-1583$.

15. Gotberg M, et al. Rapid short-duration hypothermia with cold saline and endovascular cooling before reperfusion reduces microvascular obstruction and myocardial infarct size. BMC Cardiovasc Disord 2008;8:7.

16. Hamamoto $\mathrm{H}$, et al. Very mild hypothermia during ischemia and reperfusion improves postinfarction ventricular remodeling. Ann Thorac Surg 2009;87:172-177.

17. Dixon SR, et al. Induction of mild systemic hypothermia with endovascular cooling during primary percutaneous coronary intervention for acute myocardial infarction. J Am Coll Cardiol 2002;40:1928-1934.

18. Kandzari DE, et al. Feasibility of endovascular cooling as an adjunct to primary percutaneous coronary intervention (results of the LOWTEMP pilot study). Am J Cardiol 2004;93:636-639.

19. Ly HQ, et al. A pilot study: The Noninvasive Surface Cooling Thermoregulatory System for Mild Hypothermia Induction in Acute Myocardial Infarction (the NICAMI Study). Am Heart J 2005; $150: 933$.

20. Gotberg M, et al. A pilot study of rapid cooling by cold saline and endovascular cooling before reperfusion in patients with ST-elevation myocardial infarction. Circ Cardiovasc Interv 2010;3:400-407.

21. Erlinge D, et al. Rapid endovascular catheter core cooling combined with cold saline as an adjunct to percutaneous coronary intervention for the treatment of acute myocardial infarction. The CHILL-MI trial: A randomized controlled study of the use of central venous catheter core cooling combined with cold saline as an adjunct to percutaneous coronary intervention for the treatment of acute myocardial infarction. J Am Coll Cardiol 2014;63:1857-1865.

22. Grines CL. Intravascular cooling adjunctive to percutaneous coronary intervention for acute myocardial infarction. Presented at the 16th annual Transcatheter Cardiovascular Therapeutics, Washington DC, USA, September 2004.
23. O'Neill WW, Dixon SR, Grines CL. The year in interventional cardiology. J Am Coll Cardiol 2005;45:1117-1134.

24. Erlinge D, et al. A pooled analysis of the effect of endovascular cooling on infarct size in patients with ST-elevation myocardial infarction. EuroIntervention 2013;8:1435-1440.

25. Kim H, et al. Feasibility and safety of regional myocardial hypothermia during myocardial ischemia and infarction in pigs. Coron Artery Dis 2005;16:125-129.

26. van't Veer M, et al. Continuous infusion thermodilution for assessment of coronary flow: Theoretical background and in vitro validation. Med Eng Phys 2009;31:688-694.

27. Aarnoudse W, et al. Direct volumetric blood flow measurement in coronary arteries by thermodilution. J Am Coll Cardiol 2007; 50:2294-2304.

28. Wijnbergen I, Van't Veer M, Lammers J, Ubachs J, Pijls N. Absolute coronary blood flow measurement and microvascular resistance in ST-elevation myocardial infarction in the acute and subacute phase. Submitted.

29. Ito H, et al. Clinical implications of the 'no reflow' phenomenon. A predictor of complications and left ventricular remodeling in reperfused anterior wall myocardial infarction. Circulation 1996;93:223-228.

30. Krug A, Du Mesnil de R, Korb G. Blood supply of the myocardium after temporary coronary occlusion. Circ Res 1966;19:57-62.

31. Dave RH, Hale SL, Kloner RA. Hypothermic, closed circuit pericardioperfusion: A potential cardioprotective technique in acute regional ischemia. J Am Coll Cardiol 1998;31:1667-1671.

32. Ferrari R, et al. Occurrence of oxidative stress during reperfusion of the human heart. Circulation 1990;81:201-211.

33. Kloner RA, Przyklenk K, Whittaker P. Deleterious effects of oxygen radicals in ischemia/reperfusion. Resolved and unresolved issues. Circulation, 1989;80:1115-1127.

34. Li D, et al. Expression of lectin-like oxidized low-density lipoprotein receptors during ischemia-reperfusion and its role in determination of apoptosis and left ventricular dysfunction. J Am Coll Cardiol 2003;41:1048-1055.

35. Herskowitz A, et al. Cytokine mRNA expression in postischemic/reperfused myocardium. Am J Pathol 1995;146:419-428.

36. Suzuki K, et al. Overexpression of interleukin-1 receptor antagonist provides cardioprotection against ischemia-reperfusion injury associated with reduction in apoptosis. Circulation 2001; 104:I308-I313.

37. Hale SL, Dae MW, Kloner RA. Hypothermia during reperfusion limits 'no-reflow' injury in a rabbit model of acute myocardial infarction. Cardiovasc Res 2003;59:715-722.

38. Eidelman Y, et al. The effects of topical hypothermia and steroids on ATP levels in an in vivo liver ischemia model. J Trauma 1994;37:677-681.

39. Ning XH, et al. Temperature threshold and modulation of energy metabolism in the cardioplegic arrested rabbit heart. Cryobiology 1998;36:2-11.

40. Simkhovich BZ, Hale SL, Kloner RA. Metabolic mechanism by which mild regional hypothermia preserves ischemic tissue. J Cardiovasc Pharmacol Ther 2004;9:83-90.

41. O'Neill WW. A prospective, randomized trial of mild systemic hypothermia during PCI treatment of ST elevation MI. Presented at Transcatheter Cardiovascular Therapeutics, Washington DC, USA, 2004.

42. de Hart J, et al. An ex vivo platform to simulate cardiac physiology: A new dimension for therapy development and assessment. Int J Artif Organs2011;34:495-505. 